\title{
EVALUATION OF SAUDI DENTAL STUDENTS' AWARENESS ABOUT PREVENTIVE DENTISTRY
}

\author{
Rehab H. Allam*
}

\begin{abstract}
Aim: Knowledge and oral health behavior of dental students play an important role in oral health education of patients and community at large. It is therefore important that their own oral health behavior conforms to expectations of the population. Hence, the aim of this study was to evaluate the awareness of future dental graduates towards preventive dentistry regarding gender and level of education.
\end{abstract}

Materials and methods: The self-administered English- language structured questionnaire had two parts: The first part included gender and year of study. The second part included 9 questions to evaluate knowledge about preventive dentistry. The data were recorded and analyzed using the SPSS software. The level of statistical significance was set at $\mathrm{P}<0.05$.

Results: This cross-sectional study was performed on 207 dental students of King Saud University, dental college, Riyadh with a response rate of $80.5 \%$.

Majority of dental students were aware about the role of sugar in caries process. Generally, female students were more knowledgeable than male students in preventive dentistry. Fifth year students were more knowledgeable about the three fundamental issues of preventive dentistry, in comparison to fourth year students.

Conclusions: Dental students of King Saud University Riyadh had a sufficient level of awareness about preventive dentistry but female students were not aware enough about the role of fluoride in the prevention of dental caries.

KEY WORDS: Preventive dentistry, knowledge, dental students, caries, fluoride.

\section{INTRODUCTION}

Dental caries is an infectious and transmissible disease affecting 60-90 percent of school children and is virtually universal among adults in the majority of countries ${ }^{1}$. In Saudi Arabia it is a major public health concern in the children and is the main cause of tooth mortality, presentation of dental emergencies and tooth extraction in this group. The many causes of dental caries may include poor dietary habits, poor oral hygiene and lack of dental care $^{2,3}$

* Lecturer at King Saud University (Dental College) Pediatric Dentistry and Orthodontics Department, Saudi Arabia, Riyadh 
Preventive approach in dental practice has been cited as a reason for caries decline in recent decades ${ }^{4}$, and as a predominant part of the service-mix of dental practices in the future ${ }^{5}$. The reorientation of oral health services toward prevention and health promotion is one of WHO's priority action areas for the continuous improvement of oral health ${ }^{6}$. However, despite the wealth of evidence supporting the application of preventive practices in primary dental care, these practices are not fully implemented ${ }^{7}$.

As dental science develops, dentists are forced to update their knowledge using the latest scientific sources available. The treatment plan of each dentist is influenced by his attitude towards treatment methods and their clinical significance ${ }^{8,9}$.

A dental student is expected to be a good model for oral health behavior. As a health care provider dental students are expected to instruct their friends, family members, patients and their society to maintain good oral health ${ }^{10}$.

Upon searching different electronic databases, no studies were found to have evaluated Saudi dental students' preventive knowledge. Therefore, this present study aimed to evaluate the knowledge and attitude of future dentistry graduates about preventive dentistry according to their gender and entrance year.

\section{MATERIALS AND METHODS}

This descriptive cross-sectional study was conducted at King Saud University in the city of Riyadh. Ethical approval was obtained for this research from the College of Dentistry Research Committee (CDRC).

A self-administered structured questionnaire was distributed by hand at the beginning of scheduled classes to all undergraduate fourth and fifth year students in both male and female campuses (Girl University Campus and Boy University Campus) at the college of Dentistry in King Saud University in October 2017.

Each student was given a questionnaire to evaluate the knowledge on preventive dentistry. The questionnaire included 9 statements related to caries, fluoride and oral hygiene. The questionnaire was adapted from a current article by Nilchian et al ${ }^{11}$. A cover letter was attached to the questionnaire clarifying the purpose of the study, consent to participate, confidentiality of the information provided as well as voluntary participation. The questionnaire had two parts; demographics which included gender and year of study. The second part included 9 questions (1 item) related to sugar consumption, (1 item) related to sugar free chewing gum, (1 item) xylitol, (1 item) regular dental visits, (4 items) fluoride, and (1 item) oral hygiene. The answers to the second part of the questionnaire were scored on a 5-point Lickert scale ranging from 1 (completely disagree) to 5 (completely agree). The total score of each question shows how knowledgeable the participant is about preventive dentistry. Translation of the survey was not necessary as dentistry is taught in the English language in the college of dentistry, King Saud University.

Before starting distributing the questionnaires, pilot questionnaires were applied for 15 students to evaluate the ease of reading, clarity of the wording and understanding of the questions as it was necessary to check the students' perception and interpretation of the questions. No modifications were done for the questionnaire. The students who participated in the pilot study we not included in the final sample.

Data was analyzed using SPSS software, version 22. Data analysis was done according to gender and level of education. The $\mathrm{P}$ value $<0.05$ was adopted as significant levels.

\section{RESULTS}

A total of 207 students participated in the study from a total of 257 students. The total response 
rate was $80.5 \%$. The response rate for the fourth year was $82 \%(105 / 128)$ and for the fifth year $79 \%$ (102/129). 108 male students and 99 female students participated in the study.

According to gender distribution; in the fourth year $n=57$ were male and $n=48$ were female students while in the fifth year; males and females were equal in number $\mathrm{n}=51$

Upon comparing knowledge between male students and female students, the mean score to each question is shown in table 1 . Generally, female students were more knowledgeable than male students in preventive dentistry.

TABLE (1) The average mean of students' score in response to the 9 statements separated by gender

\begin{tabular}{|l|c|c|c|}
\hline \multicolumn{1}{|c|}{ Questions } & Male & Female & Total \\
\hline $\begin{array}{c}\text { 1. Frequency of sugar } \\
\text { consumption }\end{array}$ & 3.96 & 4.78 & 4.36 \\
\hline 2. Sugar-free chewing gum & 4.11 & 4.32 & 4.21 \\
\hline 3. Importance of xylitol & 3.17 & 3.38 & 3.27 \\
\hline 4. Regular dental visits & 4.76 & 4.95 & 4.85 \\
\hline $\begin{array}{c}\text { 5. The importance of fluoride } \\
\text { toothpaste }\end{array}$ & 3.35 & 2.91 & 3.14 \\
\hline $\begin{array}{c}\text { 6. Fluoride is the most } \\
\text { important factor for tooth } \\
\text { susceptibility to decay. }\end{array}$ & 3.41 & 3.32 & 3.36 \\
\hline $\begin{array}{c}\text { 7. Fluoridation of drinking } \\
\text { water }\end{array}$ & 4.27 & 4.42 & 4.34 \\
\hline 8. Fluoride toothpaste & 3.97 & 4.40 & 4.18 \\
\hline 9. Regular brushing & 4.51 & 4.77 & 4.64 \\
\hline Total score & 35.51 & 37.25 & 36.35 \\
\hline
\end{tabular}

Total scores of students were divided into 3 groups: students with a total score $<27$ were rated as poor in knowledge, students with total scores (28-36) were considered to have intermediate knowledge, and students with total score (37-45) were considered to have high knowledge. Fifth year students were more knowledgeable about the three fundamental issues of preventive dentistry, in comparison to fourth year students. There was a significant difference in knowledge between $4^{\text {th }}$ and $5^{\text {th }}$ year students $(\mathrm{P}=0.000)$. Moreover, female students were more knowledgeable in comparison to male students. There was a significant difference between the two genders $(\mathrm{P}<0.05)$ (Table 2).

TABLE (2) The students' knowledge level separated by year of entrance and gender

\begin{tabular}{|c|c|c|c|c|c|}
\hline & & $\begin{array}{c}\text { High } \\
(\boldsymbol{\%})\end{array}$ & $\begin{array}{c}\text { Intermediate } \\
(\boldsymbol{\%})\end{array}$ & $\begin{array}{c}\text { Poor } \\
(\boldsymbol{\%})\end{array}$ & $\begin{array}{c}\text { p- } \\
\text { value }\end{array}$ \\
\hline \multirow{2}{*}{$\begin{array}{c}\text { Entrance } \\
\text { year }\end{array}$} & 4th year & 36.1 & 61 & 2.9 & \multirow{2}{*}{0.000} \\
\cline { 2 - 6 } & 5 th year & 64.7 & 35.3 & 0 & \\
\hline \multirow{2}{*}{ Gender } & Male & 42.2 & 56 & 1.8 & \multirow{2}{*}{0.04} \\
\cline { 2 - 6 } & Female & 59.4 & 39.6 & 1 & \\
\hline
\end{tabular}

Upon examining genders within each school year; in the fourth year, female students were more knowledgeable about preventive dentistry in comparison with their male peers, but there was no significant difference between them. However, upon comparing genders in fifth year; female students had significantly better knowledge than male students $(\mathrm{P}<0.05)$.

TABLE (3) Shows the difference of gender knowledge in the same level of entrance

\begin{tabular}{|c|c|c|c|c|}
\hline Level & Gender & $\mathrm{n}$ & Score & p-value \\
\hline \multirow{2}{*}{$\begin{array}{c}\text { Fourth } \\
\text { year }\end{array}$} & Male & 57 & $34.47(4.41)$ & \multirow{2}{*}{0.129} \\
\cline { 2 - 4 } & Female & 48 & $35.62(3.28)$ & \\
\hline \multirow{2}{*}{$\begin{array}{c}\text { Fifth } \\
\text { year }\end{array}$} & Male & 51 & $36.43(3.74)$ & \multirow{2}{*}{0.003} \\
\cline { 2 - 4 } & Female & 51 & $38.35(2.62)$ & \\
\hline
\end{tabular}




\section{DISCUSSION}

The attitudes of dental practitioners toward preventive dentistry is an important factor that can influence their decision to apply preventive dental care $^{8}$ and may potentially affect their ability to motivate patients to receive dental care measures ${ }^{12}$.

Evaluating preventive knowledge of Jordanian students showed that dental preventive courses had improved dental students' oral health awareness and attitudes. Therefore Barrieshi-Nusair et al concluded that preventive dentistry courses should be taught early in the dental curriculum in preclinical years ${ }^{10}$, which is the case in the college of dentistry at king Saud University, where students are given dental public health courses in the early preclinical years of studying.

The results of this study show that dental students at King Saud University had acceptable levels of knowledge about the effect of sugar, fluoride and caries prevention. Female students had significantly better knowledge in preventive dentistry when compared with their peer male students. This is in line with previous findings 13,14. Moreover, within each academic year, female students had better knowledge than male students, but a significant difference was only observed among fifth year students. This difference might be attributed to background differences between the two genders, since women has been shown to run a more conservative style of dental practice compared to men ${ }^{15}$. However, female students in this study lacked information in two items related to the importance of fluoride in comparison to male students. This finding in consistent with a study done on Mongolian dentists in which there was an underestimate of the role of fluoride in caries prevention in comparisons to brushing technique ${ }^{16}$. While in Finland, with a long history of caries prevention, dentist regard fluoride as an important caries preventive measure ${ }^{17}$.

The results of this study also shows a significant difference in knowledge in preventive dentistry, where Fifth year students were more knowledgeable as compared to fourth year students. This could be due to that fifth year students have had more training and experience in clinical practice as compared to the younger fourth year students. These findings are in agreement with previous studies ${ }^{18,19}$.

This study was conducted in one dental school in Riyadh. This would limit the results and the conclusions drawn from it. It would be very interesting to examine if such results would be applicable to the other dental schools and other neighboring schools in the region.

\section{CONCLUSION}

It is the responsibility of dental educators to increase their students' awareness and knowledge of preventive dentistry. This will help them to play more effective role in promoting the oral health of their communities. It was concluded that dental students of King Saud University (dental collage) had sufficient level of awareness in preventive dentistry, but female students were not aware enough about the role of fluoride in the prevention of dental caries.

\section{REFERENCES}

1. Petersen PE, Bourgeois D, Ogawa H, Estupinan-Day S, Ndiaye $\mathrm{C}$. The global burden of oral diseases and risks to oral health. Bulletin of the World Health Organization. 2005 Sep;83(9):661-9.

2. Bello LB, Al-Sehaibany F, Adenubi JO. Problems presented by children attending emergency rooms: the dental clinic in Riyadh. Saudi dental journal. 1995;7:12-6.

3. Farsi JM. Common causes of extraction of teeth in Saudi Arabia. Saudi Dent J. 1992;4(3):101-05.

4. Petersson GH, Bratthall D. The caries decline: a review of reviews. European Journal of Oral Sciences. 1996 Aug 1; 104(4):436-43.

5. Eklund SA. Changing treatment patterns. The Journal of the American Dental Association. 1999 Dec 1;130(12): 1707-12. 
6. Petersen PE, Estupinan-Day S, Ndiaye C. WHO's action for continuous improvement in oral health. Bulletin of the World Health Organization. 2005 Sep;83(9):642-.

7. Garcia RI, Sohn W. The paradigm shift to prevention and its relationship to dental education. Journal of dental education. 2012 Jan 1;76(1):36-45.

8. McGlone P, Watt R, Sheiham A. Evidence-based dentistry: an overview of the challenges in changing professional practice. British dental journal. 2001 Jun 23;190(12).

9. Brown G, Manogue M, Rohlin M. Assessing attitudes in dental education: is it worthwhile?. British dental journal. 2002. Dec 21;193(12):703-7.

10. Barrieshi-Nusair K, Alomari Q, Said K. Dental health attitudes and behaviour among dental students in Jordan. Community dental health. 2006 Sep 1;23(3):147.

11. Nilchian F, Kazemi S, Abbasi M, Ghoreishian F, Kowkabi M. Evaluation of Isfahan's Dental Students' Awareness about Preventive Dentistry. Journal of Dentistry. 2014 Mar;15(1):1.

12. Ghasemi H, Murtomaa H, Torabzadeh H, Vehkalahti MM. Perceived barriers to the provision of preventive care among Iranian dentists. Oral health \& preventive dentistry. 2009 Jan 1;7(4):339.
13. Khami MR, Virtanen JI, Jafarian M, Murtomaa H. Oral health behaviour of Iranian dental school educators. Oral health \& preventive dentistry. 2006 Sep 1;4(4).

14. Ghasemi H, Murtomaa H, Torabzadeh H, Vehkalahti MM. Knowledge of and attitudes towards preventive dental care among Iranian dentists. European journal of dentistry. 2007 Oct;1(4):222.

15. Tan PL, Evans RW, Morgan MV. Caries, bitewings, and treatment decisions. Australian dental journal. 2002 Jun 1;47(2):138-41.

16. Tseveenjav B. Preventive dentistry in Mongolia. Academic dissertation, University of Helsinki,2004.

17. Vehkalahti MM, Widström E. Teaching received in caries prevention and perceived need for Best Practice Guidelines among recent graduates in Finland. European Journal of Dental Education. 2004 Feb 1;8(1):7-11.

18. Peker I, Alkurt MT. Oral health attitudes and behavior among a group of Turkish dental students. European journal of dentistry. 2009 Jan;3(1):24.

19. Polychronopoulou A, Kawamura M, Athanasouli T. Oral self-care behavior among dental school students in Greece. Journal of oral science. 2002;44(2):73-8. 